\title{
Las situaciones matrimoniales canónicas irregulares, a la luz de la exhortación apostólica Evangelli gaudium del Papa Francisco*
}

\author{
Juan Guillermo Durán Mantilla* \\ Recibido: 10 de enero de $2014 \cdot$ Revisado: 20 de febrero 2014 \\ Aprobado: 8 de marzo de 2014.
}

\section{Resumen}

El presente artículo de reflexión busca desarrollar y avalar, con la Exhortación Apostólica Evangelii Gaudium del papa Francisco, un artículo del mismo autor acerca de la necesidad de establecer mecanismos de reforma a la situación de los católicos casados canónicamente y vueltos a casar civilmente, los cuales hoy por hoy con la actual disciplina eclesial, son excluidos de los sacramentos de la confesión y de la comunión, razón por la cual se los tiene por parte de la Iglesia, y en consecuencia se consideran a sí mismos como cristianos de segunda categoría, cuando no excluidos y excomulgados, y con lo cual la lex suprema de la Iglesia Católica, que es la salvación de las almas, queda, por decirlo así, sin aplicación real.

Palabras clave: matrimonio, confesión, comunión, irregularidad, pastoral, Evangelio, misericordia, renovación.

"Este artículo es producto del proyecto de investigación "Fundamentación del Derecho" enmarcado en el Grupo de Investigación: Raimundo de Peñafort de la Universidad Santo Tomas Colombia (sede Bogotá). El citado proyecto de investigación está financiado con el apoyo económico de la mencionada Universidad.

“" Doctor en Derecho, Universidad de Navarra (España), docente Investigador y catedrático de las Universidades Santo Tomas (sede Bogotá) y Católica - CISJUC. Correo electrónico: juanduran@ usantotomas.edu.co 


\title{
CANONICAL MARRIAGE IRREgULAR SITUATIONS IN LIGHT OF THE apostolic exhortation eVangelit gaudium Francisco Pope
}

\begin{abstract}
Marriage Canonical Irregular Situations in the light of the exhortation of Pope's Francis apostolic Evangelli Gaudium.

The present reflextion paper heads to develop and approve with the Apostolic Exhortation Evangelii Gaudium of Pope Francis, an article of the same author about the necessity of settle reform mechanisms to the canonically married catholics situation and civilly get married again, that with the church discipline are rejected of the confession and communion sacraments and considered as second category Christians but not excluded and excommunicated, making the supreme lex of catholic church inapplicable which is the soul salvation.

Keywords: Marriage, confession, communion, irregularity, pastoral, Gospel, mercy, renovation.

\section{As SITUAÇõES MATRIMONIAIS CANÔNICAS IRREGULARES, À LUZ DA EXortação apostólica eVANGELII gaUdium do Papa Francisco.}

\section{Resumo}

Este artigo de reflexão procura desenvolver e apoiar, com a Exortação Apostólica Evangelii Gaudium do papa Francisco, um artigo do mesmo autor sobre a necessidade de estabelecer mecanismos para reformar a situação dos católicos casados canonicamente e voltados a casar civilmente, os quais hoje, com a atual disciplina eclesial, são excluídos dos sacramentos da confissão e da comunhão, razão pela qual se os tem pela Igreja, e, portanto, consideram-se a sim mesmos como cristãos de segunda classe, quando não excluídos e excomungados, e, portanto, a lex suprema da Igreja Católica, que é a salvação das almas, fica, por assim dizer, sem aplicação real.

Palavras-chave: casamento, confissão, comunhão, irregularidade, pastoral, Evangelho, misericórdia, renovação 


\section{Introducción}

\section{Razón de ser de esta reflexión y algunas advertencias.}

Para comenzar estas reflexiones vienen muy bien unas palabras del papa Francisco a Antonio Spadaro S.J. en el año 2013, poco después de comenzar su Pontificado (cf. Antonio Spadaro, 2013, p. 12), la misión de la Iglesia Católica hoy es como la de un hospital de campaña; no está para dar complicadas recetas sino para curar heridas inmediatas so pena de que los moribundos mueran rápidamente; es una especie de ayuda boca a boca. Ciertamente la Iglesia Católica tiene materias qué criticar de la posmodernidad en la que estamos viviendo -sin demeritarla del todo-, pero no se trata tanto de quejarse de los excesos o desvíos de esa posmodernidad cuanto de salir a socorrer a los malheridos que esta ha dejado en el camino; al fin y al cabo la misión de la Iglesia, como dijo Jesucristo de sí mismo, no es condenar, sino salvar.

Leyendo la Exhortación Apostólica Evangelii Gaudium ${ }^{1}$ del papa Francisco del año 2013, y con la mentalidad propia de abogado canonista -que eso soy-aunque al mismo tiempo con mentalidad de católico preocupado por la situación de muchos católicos que no encuentran una salida canónica a su fracaso matrimonial, o por razones de conciencia no se animan a realizar un proceso de nulidad matrimonial, o han tenido una sentencia de nulidad matrimonial negativa que quizá no comparten, y se han vuelto a casar por lo civil -sin haber obtenido previamente la anulación del matrimonio sacramental-, y que, como consecuencia de lo anterior, la Iglesia por razones disciplinarias les niega la confesión y la comunión sacramentales, descubrí que, para esos católicos, la Exhortación Apostólica mencionada arriba, puede arrojar unas luces que quisiera traer a colación y reflexionar en este escrito. Esta Exhortación resultó, pues, un verdadero desarrollo y aplicación de aquellas palabras del papa Francisco a Antonio Spadaro antes recordadas.

La urgencia de estas reflexiones se debe a que dichos católicos se encuentran en una situación de discriminación, de exclusión, o digámoslo más crudamente,

${ }^{1}$ Dedicada a la evangelización y renovación de la Iglesia desde la alegría; dice textualmente la Exhortación: "1.- La alegría del Evangelio llena el corazón y la vida entera de los que se encuentran con Jesús. Quienes se dejan salvar por Él son liberados del pecado, de la tristeza, del vacío interior, del aislamiento. Con Jesucristo siempre nace y renace la alegría. En esta Exhortación quiero dirigirme a los fieles cristianos para invitarlos a una etapa evangelizadora marcada por esa alegría, e indicar caminos para la marcha de la Iglesia en los próximos años" (Francisco, Evangelii Gaudium, San Pablo, Bogotá, 2014). 
de excomunión práctica (no técnicamente según el derecho penal de la Iglesia), porque no pueden confesarse ni comulgar sacramentalmente, lo cual les hace la vida cristiana dura en extremo; ciertamente a estos católicos la Iglesia les invita a hacer comuniones espirituales, pero son solo preparatorias de la comunión sacramental sin poder hacerla de hecho ${ }^{2}$; y como me ocupo también de los derechos humanos en mi quehacer universitario, esta discriminación, exclusión, o excomunión práctica, es asunto que me preocupa y atañe. A dichos católicos dedico prioritariamente estas líneas, pero también a la jerarquía y a los sacerdotes para que pastoral y jurídicamente se ponderen, así como a la comunidad eclesial en general.

Estas consideraciones que aquí presento son una prolongación de un artículo que escribí (cfr. Juan Guillermo Durán, La salvación de las almas, 2014), al cual, desde luego, remito como materia prima sine qua non de este; son una especie de confirmación de ese artículo (perdóneseme la posible imagen arrogante que pueda conllevar tal expresión; en realidad si hablo de prolongación y confirmación lo hago con sentimiento de alegría y no de arrogancia).

Como es apenas obvio trataré de presentar a continuación un resumen de dicho artículo antes de proseguir, a fin de facilitar al lector la comprensión de estas reflexiones:

Allí manifesté dos bloques temáticos: uno sustantivo y otro procesal; acerca del primero dije que es menester mirar las palabras de Cristo acerca de la indisolubilidad del matrimonio, en combinación y armonización con sus palabras sobre el perdón de los pecados, así como también debe mirarse dicha indisolubilidad a la luz de lo sustancial más que de las apariencias matrimoniales; se manifestó también la conveniencia de adaptar en el seno de la Iglesia Católica romana la teoría y praxis en situación de ruptura matrimonial que realiza la Iglesia Católica Ortodoxa; esta dice que se puede admitir al matrimonio sacramental hasta tres veces -desde luego estando supérstites los anteriores cónyuges-, si se dan ciertas condiciones tales como pedir perdón a Dios por haber causado la ruptura matrimonial anterior, pedir perdón al cónyuge víctima, y arreglar la situación de separación ante la ley civil; también propuse la conveniencia de adoptar legislativamente -o incluso jurisprudencialmente- la causal de nulidad de la "grave" incompatibilidad de caracteres.

\footnotetext{
${ }^{2}$ El Sínodo Extraordinario de los Obispos del año 2014, en el numeral 48 de la Relatio dice, dando a mi juicio un paso más adelante: "sugerir de limitarse a la sola "comunión espiritual" para no pocos padres sinodales plantea algunas preguntas: ¿si es posible la comunión espiritual, por qué no es posible acceder a la sacramental?..."(Relatio post disceptationem): http://press.vatican.va/content/salastampa/es/ bolletino/pubblico/2014/10/13/0751/03037
} 
Respecto a lo meramente procesal, proponía una serie de reformas tales como: abolir las dos sentencias conformes dentro del mismo proceso de anulación matrimonial canónica; establecer la causal de prescripción del matrimonio cuando este es irreal en la praxis; no exigir siempre y en todos los casos pruebas testimoniales cuando estas son verdaderamente imposibles de recabar, o inútiles; establecer la causal del común acuerdo de ambos cónyuges como causal de anulación matrimonial; establecer el fin o terminación del amor conyugal como causal de anulación del matrimonio canónico; y establecer un trámite administrativo para el caso de adoptar la teoría y praxis del perdón propias la Iglesia Católica Ortodoxa.

El abordaje de estas meditaciones transcurre tomando los puntos de la encíclica que he considerado más pertinentes para el desarrollo de la tesis que he venido trabajando, postura según la cual a mi juicio pueden y deben abrirse caminos para solucionar la situación de tantos católicos casados por la Iglesia, que han sufrido el fracaso de su matrimonio, y se han vuelto a casar por lo civil sin haber podido resolver antes satisfactoriamente su situación canónica matrimonial. Dichos puntos, unos son indirectos o de animación general, y otros más directos o expresos respecto al punto a tratar mencionado; tal perspectiva me ha servido para dividir la exposición a fin de hacerla más pedagógica. Es fácil captar, en consecuencia, que la fuente por antonomasia para el tratamiento de mi tesis es la mencionada Exhortación Apostólica Evangelii Gaudium; desde ella, el resto son fuentes accesorias o simples comentarios.

De antemano en ningún momento se pretende poner en tela de juicio la necesidad de la "institucionalidad" del matrimonio; al contrario, es considerada necesaria no solo por las palabras de Cristo -que para un creyente son luz-, acerca de que el matrimonio es indisoluble, sino por una necesidad humana visible y ostensible de permanencia sana de la vida en pareja, máxime hoy cuando por la mentalidad posmoderna el hombre se ha tornado individualista, atomizado y atomizante, peligro que se agrava con la superpoblación mundial que hace más imperativa la necesidad de instituciones y normas de convivencia.

Se deja por sentado previamente que ante las crisis matrimoniales no solo debe recurrirse, en lo posible, al expediente canónico procesal matrimonial, sino que, antes de las rupturas, deben ponerse todos los medios para salvar el matrimonio: retiros espirituales, terapias de pareja, esfuerzos de todo tipo por parte de los esposos, etc. No podemos seguir el camino más cómodo, sino que para el creyente la cruz, la puerta estrecha -también palabras de Cristo que iluminan-, deben ser 
sendas a seguir y "puerta estrecha" que se traduce en poner los medios para salvar el matrimonio, o, que si no se ha salvado, empezar el trámite procesal del proceso de anulación matrimonial (estas últimas ideas las enfatizó el investigador y profesor universitario Oscar Leonardo Aguillón Duarte, quien se menciona aquí en señal de agradecimiento).

\section{Animación general para la renovación de la situación matrimonial canónica irregular}

Dicho lo anterior, se analiza la Evangelii Gaudium -E.A.- en lo que puede servirnos para iluminar, en general, la renovación del tratamiento de la situación matrimonial canónica irregular.

Antes de comenzar, debe tenerse en cuenta que la Exhortación apostólica familiaris consortio, del papa Juan Pablo II, en los años 80 del siglo $\mathrm{XX}^{3}$, fue la que comenzó a hablar de "situaciones irregulares" de los católicos casados canónicamente y vueltos a casar por lo civil, y también en dicho documento papal se establecieron formas de acompañamiento a esos católicos por parte de la Iglesia; fue un primer paso, hay que reconocerlo; pero, posteriormente, se han dado otros de mayor apertura a esos católicos; este que estamos dando a la luz de la Evangelii Gaudium, es uno más a nuestro juicio.

a. Desde las primeras páginas, la Evangelii Gaudium va preparando, introduciendo en esa renovación. Así, en el numeral 11, se dice:

Jesucristo también puede romper los esquemas aburridos en los cuales pretendemos encerrarlo y nos sorprende con su constante creatividad divina. Cada vez que intentamos volver a la fuente y recuperar la frescura original del Evangelio, brotan nuevos caminos, métodos creativos, otras formas de expresión, signos más elocuentes, palabras cargadas de renovado significado para el mundo actual. En realidad, toda auténtica acción evangelizadora es siempre 'nueva'.

De esas palabras bien podemos quedarnos con estas, si queremos (cada uno elija las que quiera y le sean más luminosas): "brotan nuevos caminos".

En efecto, Cristo trajo "vino nuevo" que debe echarse en "cueros nuevos" como Él mismo lo dijo; por ejemplo, trajo el mandamiento nuevo del amor, que es su

${ }^{3}$ Juan Pablo II, familiaris consortio, 1981. A este pontífice se le ha llamado, no solo por este documento sino por múltiples actividades más en torno a ella, el papa de la familia. 
mandatum novum; Dios es infinito, y, desde Él, se deben imaginar cosas nuevas. Desde luego Cristo habló del pasado, de que no venía a abolir la ley y los profetas sino a darles su pleno cumplimento, pero qué duda cabe que en Él hay una novedad infinita por ser el Hijo de Dios.

Debido a esa posibilidad de la novedad de Cristo, es que cabe explorar nuevos caminos de evangelización, y concretamente en el terreno que nos ocup $\mathrm{a}^{4}$.

b. Tomemos ahora las siguientes palabras del numeral 15:

En esta linea, los Obispos latinoamericanos afirmaron que ya no podemos quedarnos tranquilos en espera pasiva en nuestros templos' y que hace pasar 'de una pastoral de mera conservación a una pastoral decididamente misionera'. Esta tarea sigue siendo la fuente de las mayores alegrias para la Iglesia: 'babrá más gozo en el cielo por un solo pecador que se convierta, que por noventa y nueve justos que no necesitan convertirse'.

De las anteriores palabras se recogen ahora estas: "no podemos quedarnos tranquilos en espera pasiva".

La tranquilidad de la seguridad es nociva si no se es consciente de nuevas realidades que gritan por sí mismas que sean reconsideradas con nuevas luces; esa mala tranquilidad es comodidad, apoltronamiento, envejecimiento; el cristianismo no es pasividad, por el contrario es acción continua en medio del mundo desde la contemplación: Id por todo el mundo y predicad el Evangelio, mandó Jesús a sus discípulos; "id" es distinto a esperar que los demás vengan a uno. Más adelante el papa Francisco, en concordancia con esta idea, va a exhortar diciendo que "ya no nos sirve una 'simple administración'. Constituyámonos en todas las naciones de la tierra en 'estado permanente de misión”', dirá en el numeral 25.

En este punto hago auto-referencia al artículo de mi autoría que trata de la necesaria compaginación de las palabras de Cristo sobre la indisolubilidad del matrimonio, y el perdón al pecador, compaginación que sabe muy bien aplicar la Iglesia Católica Ortodoxa, al armonizar la indisolubilidad y la pastoralidad, la sustancialidad del matrimonio y la realidad pecadora del hombre, razón por la cual

${ }^{4}$ El Sínodo Extraordinario de los Obispos del año 2014 ha dicho en el numeral 40 siguiendo esta idea: " $n$ el Sínodo ha resonado la clara necesidad de opciones pastorales valientes. Reconfirmando con fuerza la fidelidad al Evangelio de la familia, los padres sinodales, han advertido la urgencia de nuevos caminos pastorales, que partan de la efectiva realidad de las fragilidades de la familia, reconociendo que estas, la mayoría de las veces, han sido "sufridas" más que elegidas en plena libertad" (texto en negrillas es énfasis del autor). 
se puede admitir el sacramento del matrimonio hasta tres veces, estando el cónyuge afectado supérstite, si el infractor o pecador pide perdón a Dios de su falta, pide perdón al cónyuge afectado, y soluciona civilmente sus asuntos antes de contraer nuevamente el sacramento del matrimonio.

c. Vamos ahora estas otras palabras del numeral 24 de la Exhortación Apostólica Evangelii Gaudium:

La Iglesia en salida... sabe adelantarse, tomar la iniciativa sin miedo, salir al encuentro, buscar a los lejanos y llegar a los cruces de los caminos para invitar a los excluidos. Vive un deseo inagotable de brindar misericordia, fruto de haber experimentado la infinita misericordia del Padre y su fuerza difusiva... la comunidad evangelizadora se mete con obras y gestos en la vida cotidiana de los demás, achica distancias, se abaja hasta la humillación si es necesario, y asume la vida humana, tocando la carne sufriente de Cristo en el pueblo.

Se destacan las siguientes palabras del anterior trozo (que cada uno escoja las que más le "duelan" o afecten): "tomar la iniciativa sin miedo... para invitar a los excluidos. Vive un deseo inagotable de brindar misericordia”.

Más adelante, en el numeral 33, el papa Francisco va a repetir esta misma idea con apertura y sin inhibiciones: "exhorto a todos a aplicar con generosidad y valentía las orientaciones de este documento, sin prohibiciones ni miedos".

Claro está, yo imagino a los espíritus súper-tradicionalistas, súper-conservadores, aterrados ante estas palabras y diciendo de alguna manera que el papa Francisco va a acabar con la Iglesia al invitar al cambio y a la sana rebelión.

El papa Francisco invita a tomar la iniciativa, a "primerear" (lo dice con ese neologismo), basado en lo más propio del Evangelio: la misericordia. A este respecto más adelante el papa dirá una de las palabras que más me han impresionado de esta Exhortación y que valen la pena transcribirlas:

Todas las verdades reveladas proceden de la misma fuente divina y son creídas con la misma fe, pero algunas de ellas son más importantes por expresar más directamente el corazón del Evangelio. En este núcleo fundamental lo que resplandece es la belleza del amor salvifico de Dios, manifestado en Jesucristo muerto y resucitado. En este sentido, el Concilio Vaticano II explicó que 'bay un orden o 'jerarquia' en las verdades en la doctrina católica, por ser diversa su conexión con el fundamento de la fe cristiana' (numeral 36).

Y más adelante, en el numeral 38, insistirá en esta idea cuando afirma que "lo mismo sucede cuando se habla más de la ley que de la gracia, más de la Iglesia que de Jesucristo, más del papa que de la Palabra de Dios”, palabras que recuerdan el 
principio hermenéutico por antonomasia de Cristo: "no es el hombre para la ley sino la ley para el hombre".

Así, pues, ese es el meollo sobre el cual giran estas reflexiones; es lo que el Código de Derecho Canónico en su canon 1.752 llama la lex suprema de la Iglesia y del cristianismo: la salvación de las almas ${ }^{5}$. ¿Cómo no aplicarlas entonces a los católicos en situación matrimonial irregular? Sería un desperdicio para ellos no tenerlas en cuenta; y más que desperdicio, una ocultación grave, una omisión imperdonable.

d. Sigamos con las palabras que en la Exhortación Evangelii Gaudium nos van llevando de la mano a una renovación en el tratamiento de las situaciones canónicas matrimoniales irregulares, aunque casi que ya nos van metiendo directamente en ella; en efecto, dice el papa Francisco en el numeral 27:

Sueño con una opción misionera capaz de transformarlo todo, para que las costumbres, los estilos, los horarios, el lenguaje y toda estructura eclesial se convierta en un cauce adecuado para la evangelización del mundo actual más que para la autopreservación. La reforma de estructuras que exige la conversión pastoral solo puede entenderse en este sentido: procurar que todas ellas se vuelvan más misioneras, que la pastoral en todas sus instancias sea más expansiva y abierta, que coloque a los agentes pastorales en constante actitud de salida y favorezca asi la respuesta positiva de todos aquellos a quienes Jesús convoca a su amistad.

Se resaltan las siguientes palabras del anterior trozo: "sueño con una opción misionera capaz de transformarlo todo, para que las costumbres... y toda estructura eclesial se convierta en un cauce adecuado para la evangelización del mundo actual más que para la autopreservación".

Es volver a lo ya dicho acerca de la imperiosa e insoslayable aplicabilidad de la lex suprema que es la salus animarum en los casos que nos ocupan: no se trata de autopreservación cómoda sino de evangelización activa; no se trata tampoco de guardar cueros viejos sino de vigilar para que siempre haya cueros nuevos que preserven el Evangelio, que es noticia siempre novedosa; no se trata tanto de estructuras humanas que se amarillan por viejas, por meritorias que sean, sino del mensaje esencial de Cristo que es la misericordia.

${ }^{5}$ Dice este canon del Código de Derecho Canónico: "en las causas de traslado (se está refiriendo a los párrocos) es de aplicación el can. 1.747, guardando la equidad canónica y teniendo en cuenta la salvación de las almas, que debe ser siempre la ley suprema de la Iglesia" (Código de Derecho Canónico, BAC, Madrid, 1984). Esta es la base doctrinal del artículo al que se hace referencia al comenzar esta reflexión, y desde luego de este también. 
e. Siguiendo con la idea ya expuesta de invitar a primerear en todas las materias y vencer los temores, y que nosotros hemos adoptado para el tema de los matrimonios irregulares en el derecho canónico actual, dice el papa Francisco estas palabras en el numeral $\mathbf{4 0}$ de la Evangelii Gaudium:

Además, en el seno de la Iglesia hay innumerables cuestiones acerca de las cuales se investiga y se reflexiona con amplia libertad. Las distintas lineas de pensamiento filosófico, teológico y pastoral, si se dejan armonizar por el Espiritu en el respeto y el amor, también pueden hacer crecer a la Iglesia, ya que ayudan a explicitar mejor el riquísimo tesoro de la Palabra. A quienes sueñan con una doctrina monolitica defendida por todos sin matices, esto puede parecerles una imperfecta dispersión. Pero la verdad es que esa variedad ayuda a que se manifiesten $y$ desarrollen mejor los diversos aspectos de la inagotable riqueza del Evangelio.

La nota de pie de página a esta idea del papa es también digna de ser tenida en cuenta aquí; veámosla:

Santo Tomás de Aquino remarcaba que la multiplicidad y la variedad 'proviene de la intención del primer agente', quien quiso que, 'lo que faltaba a cada cosa para representar la bondad divina, fuera suplido por las otras', porque su bondad 'no podría representarse convenientemente por una sola criatura' (Summa Theologiae I, q. 47, art. 1). Por eso nosotros necesitamos captar la variedad de las cosas en sus múltiples relaciones (cf. Summa Theologiae I, q. 47, art. 2, ad. 1; q. 47, art. 3). Por razones análogas, necesitamos escucharnos unos a otros y complementarnos en nuestra captación parcial de la realidad $y$ del Evangelio.

Estas palabras autorizan y animan a expresar, sin tapujos ni miedos como pide el mismo papa Francisco, lo que mi reflexión y experiencia -desde el campo jurídico-canónico y pastoral-, me dicen en la materia, en el entendido de que todos nos podemos colaborar bajo la característica del respeto; todos formamos un tejido y todos podemos colaborarnos recíprocamente. Es, por ejemplo, la idea de acoger la teoría y praxis de la Iglesia Católica Ortodoxa.

$\mathrm{Y}$ es también una invitación a mirar los matices, las circunstancias personales de cada uno, sin querer estandarizar a todos como si fuésemos fotocopias, clones, olvidando por cierto aquella idea tan expresiva del papa Juan Pablo II de que cada hombre es "único e irrepetible”. Un filósofo de nuestro tiempo, José Ortega y Gasset, lo dijo con estas elocuentes palabras: "yo soy yo y mis circunstancias".

Hasta aquí, las palabras que nos introducen en el tema de manera general. Pasemos ahora a las ideas más directamente relacionadas con la necesaria renovación 
de la Iglesia frente a los católicos casados por el sacramento, pero que han fracasado y se vuelven a casar por lo civil.

\section{Los puntos de la Exhortación Apostólica Evangelii Gaudium que más directamente atañen a las situaciones matrimoniales irregulares}

Las ideas que más directamente conciernen a la materia que estamos tratando, las vamos a enunciar y tratar de glosar a continuación. En esta labor de sensibilidad y búsqueda del tema anotado en la E.A. (ponerle lupa, podría decirse, a dicho documento en lo que aquí se trata, leerla con esta óptica), los siguientes numerales hacen relación al tema y se dejarán anotados desde el comienzo; son ellos: 32, 43, 49, 114, 165, 169, 244, 245, y 246.

a. Para el tema que nos convoca leamos las siguientes palabras del numeral 32:

También el papado y las estructuras centrales de la Iglesia universal necesitan escuchar la llamada a una conversión pastoral. El Concilio Vaticano II expresó que, de modo análogo a las antiguas Iglesias patriarcales, las conferencias episcopales pueden 'desarrollar una obra múltiple y fecunda a fin de que el afecto colegial tenga una aplicación concreta'... una excesiva centralización, más que ayudar, complica la vida de la Iglesia y su dinámica misionera.

Como dije en el artículo de mi autoría, y refiriéndome al proceso canónico en sí, el tratamiento de los matrimonios en sede romana, cuando suben a esa instancia para lograr la doble sentencia conforme en los procesos de anulación matrimonial canónica ${ }^{6}$, no sólo viola la inmediatez sino también la celeridad procesal, necesarias para que el proceso canónico se aproxime a la justicia real y no teórica.

Aquí el papa Francisco llama fuertemente la atención sobre esa centralización romana para nada conveniente, y que ya el Concilio Vaticano II -llevado a cabo en los años 1962-1965, hace por tanto ya lejanos 50 años- dijo que no convenía, y

${ }^{6}$ El Sínodo Extraordinario de los Obispos del año 2014 prevé en el numeral 43 algo todavía más amplio y valiente: "diversos padres han subrayado la necesidad de hacer más accesibles y ágiles los procedimientos para el reconocimiento de casos de nulidad. Entre las propuestas han sido indicadas la superación de la necesidad de la doble instancia conforme; la posibilidad de determinar una vía administrativa bajo la responsabilidad del obispo diocesano; un proceso sumario para realizar en los casos de nulidad notoria...”. 
señala que más bien debería seguirse el ejemplo de las antiguas Iglesias patriarcales por parte de las conferencias episcopales de cada país de manera más concreta y realista; ¿esas Iglesias patriarcales son las de la Iglesia Católica Ortodoxa? Parece que de alguna manera sí, y ello avala la permanente referencia a la teoría y praxis de la Iglesia Católica Ortodoxa en la materia que venimos tratando y que deberían adaptarse por parte de la Iglesia Católica Romana.

La doble sentencia conforme en los procesos de anulación matrimonial canónica, bien sea en sede nacional, y más aún en sede romana (que es a lo que se refiero aquí porque el papa la menciona), está llamada, de esa manera, a desaparecer si se quiere una sana descentralización en esta materia que se está tratando ${ }^{7}$.

b. Veamos ahora el numeral 43:

En su constante discernimiento, la Iglesia también puede llegar a reconocer costumbres propias no directamente ligadas al núcleo del Evangelio, algunas muy arraigadas a lo largo de la historia, que hoy ya no son interpretadas de la misma manera y cuyo mensaje no suele ser percibido adecuadamente. Pueden ser bellas, pero ahora no prestan el mismo servicio en orden a la transmisión del Evangelio. No tengamos miedo de revisarlas. Del mismo modo, hay normas o preceptos eclesiales que pueden haber sido muy eficaces en otras épocas pero que ya no tienen la misma fuerza educativa como cauces de vida. Santo Tomás de Aquino destacaba que los preceptos dados por Cristo y los Apóstoles al Pueblo de Dios 'son poquisimos'. Citando a san Agustín, advertía que los preceptos añadidos por la Iglesia posteriormente deben exigirse con moderación 'para no hacer pesada la vida a los fieles' y convertir nuestra religión en una esclavitud cuando 'la misericordia de Dios quiso que fuera libre'. Esta advertencia, hecha varios siglos atrás, tiene una tremenda actualidad. Debería ser uno de los criterios a considerar a la hora de pensar una reforma de la Iglesia y de su predicación que permita realmente llegar a todos.

${ }^{7}$ Dice el comentarista del Código de Derecho Canónico para explicar este principio de la doble sentencia: "en las causas de nulidad del matrimonio, para que la sentencia sea firme y ejecutiva, se requieren dos sentencias conformes antes de que los esposos puedan pasar a un nuevo matrimonio (cc. 16841685)" (Código de Derecho Canónico, BAC, Madrid, 1984); en consecuencia, si en primera instancia se falló, por ejemplo, afirmativa la nulidad, y en la segunda se falló negativa, el proceso debe ir a la Rota Romana (aunque en España existe una sede de la Rota Romana, y, últimamente se ha establecido para Latinoamérica un Tribunal en Buenos Aires, que hace las veces de tercera instancia), la cual debe dar otra sentencia para así tener dos sentencias conformes; es sabido por simples razones lógicas que en Roma no hay inmediatez ni celeridad y los procesos se demoran en demasía. 
La primera parte de esta idea lleva a pensar casi que automáticamente en la liturgia, por ejemplo. En efecto, las gentes quizá no reciben de buen grado tanto boato, tantas joyas, tanto adorno, tantas capas, cuando entre las cosas que más quiere la gente del cristianismo es la sencillez, la austeridad, la pobreza-obviamente sin desmedro de la dignidad de lo sagrado-, en seguimiento de Aquel que nació en un pesebre, no tenía dónde reclinar la cabeza, y murió despojado de todo en la cruz. Pero aquí no profundizaremos más en este aspecto por no ser nuestro objeto formal de estudio en este artículo.

La segunda parte del numeral anterior es más de carácter jurídico y por eso se ha subrayado. A este tema también me he referido en el artículo de mi autoría. La dureza de las normas canónico-matrimoniales -a pesar de haberse atenuado por ejemplo en el Código de Derecho Canónico de 1983, con la introducción del c. 1.095 , entre otros ${ }^{8}$, no deja de ser una carga a veces insoportable; por eso, proponía allí en ese artículo el capítulo de la "grave" incompatibilidad de caracteres como capítulo de nulidad matrimonial, o la teoría y praxis de la Iglesia Católica Ortodoxa, como se mencionó, que por una economía pastoral permite hasta tres veces el sacramento del matrimonio dadas ciertas condiciones; igualmente en el artículo se propone desbalancear el actual binomio derecho-pastoral, inclinándome por la pastoralidad por encima de la juridicidad, así se diga, quizá equivocadamente, que la última incluye a la primera. "Equivocadamente" pues al incluirse la pastoralidad en la juridicialidad, termina esta imponiéndose. Se necesita más pastoral, más misericordia -como vimos que quiere el papa-, y menos juridicismo, menos influencia del derecho romano y de otras experiencias jurídicas históricas, en el seno de la Iglesia, en la que debe primar ante todo la misericordia?.

\footnotetext{
${ }^{8}$ Para quienes no están habituados a este canon, aquí se presenta el texto: "son incapaces de contraer matrimonio: 1.- quienes carecen de suficiente uso de razón; 2.- quienes tienen un grave defecto de discreción de juicio acerca de los derechos y deberes esenciales del matrimonio que mutuamente se han de dar y aceptar; 3.- quienes no pueden asumir las obligaciones esenciales del matrimonio por causas de naturaleza psíquica” (Código de Derecho Canónico, BAC, Madrid, 1984). Este último numeral, el tercero, es el de mayor riqueza y novedad por cuanto se introdujo la existencialidad real del matrimonio como causal de nulidad matrimonial; así, pues, se enfatizó más en dicha existencialidad que en la esencialidad teórica del matrimonio.

${ }^{9} \mathrm{La}$ Iglesia es deudora del derecho romano al menos en un momento clave de su historia: con la Codificación Justinianea, emperador ya cristiano, en el siglo VI, (cf. Ludwig Hertling, Historia de la Iglesia, p. 144) como elemento cohesionador del derecho y civilizador ante las invasiones bárbaras; es una tradición muy rica, a no dudarlo, un tesoro cultural jurídico; pero el papa actual llama a mirar críticamente su prevalencia respecto del Evangelio. Igualmente en este numeral puede advertirse que la Iglesia ha experimentado la influencia por ejemplo del fruto quizá más preciado del iuspositivismo
} 
También fijémonos que el papa Francisco llama la atención aquí acerca de normas que en otras épocas pudieron haber sido cauce de vida; pues bien, hoy en día esas normas -sin desconocer la influencia educativa de las mismas como señala Santo Tomás de Aquino-, no son el bastión contra la destrucción del matrimonio; si así fuera esas normas estarían conteniendo la disolución matrimonial actual, pero no, la destrucción matrimonial sigue in crescendo; hoy vale más el ejemplo de los esposos, la educación, la tarea civilizadora en general, que las mismas normas y el derecho, hoy muy cuestionado en general, pues asistimos a una época más amante de lo genuino y auténtico ${ }^{10}$.

c. Veamos ahora el numeral 49:

Salgamos, salgamos a ofrecer todos la vida de Jesucristo. Repito aqui para toda la Iglesia lo que muchas veces he dicho a los sacerdotes y laicos de Buenos Aires: prefiero una Iglesia accidentada, herida y manchada por salir a la calle, antes que una Iglesia enferma por el encierro y la comodidad de aferrarse a las propias seguridades. No quiero una Iglesia preocupada por el centro y que termine clausurada en una maraña de obsesiones y procedimientos. Si algo debe inquietarnos santamente y preocupar nuestra conciencia, es que tantos hermanos vivan sin la fuerza, la luz y el consuelo de la amistad con Jesucristo, sin una comunidad de fe que los contenga, sin un horizonte de sentido y de vida. Más que el temor a equivocarnos, espero que nos mueva el temor a encerrarnos en las estructuras que nos dan una falsa contención, en las normas que nos vuelven jueces implacables, en las costumbres donde nos sentimos tranquilos, mientras afuera hay una multitud hambrienta y Jesús nos repite sin cansarse: 'Dadles vosotros de comer'.

Al leer estas palabras nos acordamos enseguida de la prohibición actual para los católicos vueltos a casar (por lo civil), que no pueden ni confesarse (salvo que suspendan las relaciones íntimas, situación sencillamente absurda, inhumana y contra natura), ni comulgar, y, por tanto, verse abocados a una vida cristiana anodina, de segunda categoría, a punto de perderse para la Iglesia, y marchar a otra que, de pronto, sí los admita.

moderado del siglo XIX: la codificación, cuya primera expresión en el seno de la Iglesia Católica fue con el Código de Derecho Canónico de 1917, y luego con el Código de 1983, que, sin ponerla en duda o crítica, el papa llama a que no se siga tanto el criterio del juridicismo cuanto sí el del pastoralismo propio de los Evangelios.

${ }^{10} \mathrm{El}$ documento del Sínodo Extraordinario de los Obispos del año 2014 dice en el numeral 29: "no se trata solamente de presentar una normativa sino de proponer valores...". 
Las normas canónicas matrimoniales, entonces, tanto las sustantivas como las procesales, deben ser esencialmente misericordiosas, pastorales. La misericordia es el núcleo del Evangelio, nos recordó ya el papa Francisco, y ello supone menor rigidez normativa y judicial, menos iuspositivismo canónico. La norma de normas deberá ser el mismo Jesucristo que perdona una y mil veces y no una maraña de normas y procedimientos que hacen la vida cristiana imposible de $\operatorname{practicar}^{11}$.

d. Pasemos a transcribir ahora el numeral 114:

Ser Iglesia es ser Pueblo de Dios, de acuerdo con el gran proyecto de amor del $\mathrm{Pa}-$ dre. Esto implica ser fermento de Dios en medio de la humanidad. Quiere decir anunciar y llevar la salvación de Dios en este mundo nuestro, que a menudo se pierde, necesitado de tener respuestas que alienten, que den esperanza, que den nuevo vigor en el camino. La Iglesia tiene que ser el lugar de la misericordia gratuita, donde todo el mundo pueda sentirse acogido, amado, perdonado y alentado a vivir según la vida buena del Evangelio.

Son palabras que nos recuerdan, una vez más, la lex suprema de la Iglesia: la salus animarum, la salvación de las almas.

En el artículo ya mencionado se abordó la necesidad del perdón a los casados por la Iglesia y vueltos a casar por lo civil: la Iglesia es el lugar de esa gratuidad, de esa misericordia de Dios; Jesús, si de algo habló con especial fuerza, fue del perdón. Creo que es de las características más propias del cristianismo: "Padre, perdónalos, porque no saben lo que hacen", dejó Cristo como legado suyo en la cruz del Calvario.

e. Veamos el numeral 165:

... La centralidad del Kerygma demanda ciertas características del anuncio que hoy son necesarias en todas partes: que exprese el amor salvifico de Dios previo a la obligación moral y religiosa, que no imponga la verdad y que apele a la libertad, que posea unas notas de alegría, estimulo, vitalidad, y una integralidad armoniosa que no reduzca la predicación a unas pocas doctrinas a veces más filosóficas que

\footnotetext{
${ }^{11}$ Cómo no recordar en este momento el numeral 47 del documento del Sínodo del año 2014: "con respecto a la posibilidad de acceder a los sacramentos de la penitencia y de la eucaristía, algunos han argumentado a favor de la disciplina actual en virtud de su fundamento teológico, otros se han expresado por una mayor apertura a las condiciones bien precisas cuando se trata de situaciones que no pueden ser disueltas sin determinar nuevas injusticias y sufrimientos. Para algunos, el eventual acceso a los Sacramentos debe ir precedido de un camino penitencial... Se trataría de una posibilidad no generalizada, fruto de un discernimiento actuado caso por caso...”. Esta posición última es la que compartimos.
} 
evangélicas. Esto exige al evangelizador ciertas actitudes que ayudan a acoger mejor el anuncio: cercanía, paciencia, acogida cordial que no condena.

Las anteriores palabras nos recuerdan, otra vez, la centralidad nuclear del mensaje de salvación del Padre a través de la muerte y resurrección de Jesús, por encima de las doctrinas del mundo, incluidas las filosóficas, y, por qué no decirlo, también las jurídicas ${ }^{12}$; como se indicó: primero debe ser el Evangelio; Cristo no habló prioritariamente de las doctrinas filosóficas o jurídicas de su época por importantes que fueran; un san Pablo tampoco, a pesar de su extensa cultura. Pero, por la cercanía, la Iglesia empezó a valorar poco a poco, en demasía, las culturas de cada tiempo en que ha vivido (la griega, la romana...), y se fueron imponiendo a veces imperceptiblemente por encima del Evangelio mismo (es el caso del derecho romano como ya vimos), Evangelio cuyo eje es la misericordia, tal como se ha dicho reiterativamente.

¿Y qué decir de la "condena" que pesa sobre los casados por la Iglesia y vueltos a casar por lo civil?: se los priva de la confesión (salvo que se abstengan de las relaciones sexuales, cosa que como ya se ha dicho es prácticamente imposible), y de la comunión eucarística, por lo cual paulatinamente se van alejando de la Iglesia puesto que se sienten excluidos, excomulgados de manera práctica ${ }^{13}$.

Pero la Iglesia, como Cristo mismo, no vino a condenar sino a salvar: la salus animarum es la lex suprema de la Iglesia.

\section{f. Numeral 169:}

En una civilización paradójicamente herida de anonimato y, a la vez, obsesionada por los detalles de la vida de los demás, impudorosamente enferma de curiosidad malsana, la Iglesia necesita la mirada cercana para contemplar, conmoverse y detenerse ante el otro, cuantas veces sea necesario. En este mundo los ministros ordenados y los demás agentes pastorales pueden hacer presente la fragancia de la presencia cercana de Jesús y su mirada personal. La Iglesia tendrá que iniciar a sus hermanos -sacerdotes, religiosos y laicos-en este 'arte de acompañamiento', para que todos aprendan siempre a quitarse las sandalias ante la tierra sagrada del otro (cf. Éx 3, 5). Tenemos que darle a nuestro caminar el ritmo sanador de

12 A este respecto me remito a la nota 8 de este escrito.

${ }^{13}$ La apertura en esta materia, al contrario de esa condena, se observa en miembros insignes de la Iglesia Católica actual; así por ejemplo, entre otros, el cardenal Carlo María Martini (cf. Aldo María Valli, Historia de un hombre, p. 29), y el teólogo Walter Kasper (cfr. http://.www.aciprensa.com). 
projimidad, con una mirada respetuosa y llena de compasión pero que al mismo tiempo sane, libere y aliente a madurar en la vida cristiana.

Leyendo estas palabras me vienen a la memoria nuevamente la teoría y praxis de la Iglesia Católica Ortodoxa, que es mucho más pastoral que la romana en este punto.

También vienen a la memoria las palabras de un prelado de nuestra Iglesia Católica quien decía compungido que no puede darse, al momento de dar sentencia, aquello de decir: "pobrecitos, cómo no darles la sentencia de nulidad si se van a enterrar en vida con una sentencia negativa"; pues bien, eso es lo que hay que hacer y lo que hay que decir: pobrecitos esos católicos a quienes no se les da más compasivamente la nulidad matrimonial; es decir, hay que recurrir siempre y más a la misericordia, ACOMPAÑAR tangiblemente, como dice el papa, a esos heridos por la vida ${ }^{14}$. ¿Qué sacamos con darles una sentencia negativa si tarde o temprano -en realidad más temprano que tarde- van a unirse nuevamente con otro u otra, pues la fuerza de la atracción varón-mujer es realmente irresistible y hasta el mismo Dios desde el mismo Génesis dijo que no es bueno que el hombre esté solo (desde luego con parámetros morales)?

\section{g. Numeral 244:}

El empeño ecuménico responde a la oración del Señor Jesús que pide 'que todos sean uno' (Jn 17, 21). La credibilidad del anuncio cristiano sería mucho mayor si los cristianos superaran sus divisiones y la Iglesia realizara 'la plenitud de catolicidad que le es propia, en aquellos hijos que, incorporados a ella ciertamente por el bautismo, están, sin embargo, separados de su plena comunión'. Tenemos que recordar siempre que somos peregrinos, y peregrinamos juntos. Para eso, hay que confiar el corazón al compañero de camino sin recelos, sin desconfianzas, y mirar ante todo lo que buscamos: la paz en el rostro del único Dios. Confiarse al otro es algo artesanal, la paz es artesanal. Jesús nos dijo: ‘ Felices los que trabajan por la paz!' (Mt 5,9). En este empeño, también entre nosotros, se cumple la antigua profecia: 'de sus espadas forjarán arados' (Is 2,4).

$\mathrm{El}$ anterior numeral se complementa con el siguiente:

h. Numeral 245:

Bajo esta luz, el ecumenismo es un aporte a la unidad de la familia humana. La presencia en el Sinodo, del Patriarca de Constantinopla, su santidad Bartolomé

${ }^{14}$ El Sínodo 2014 ha insistido en el arte de acompañar por ejemplo en el numeral 23: "de acuerdo a la mirada misericordiosa de Jesús, la Iglesia debe acompañar con atención y cuidado a sus hijos más frágiles...”. 
I, y del arzobispo de Canterbury, su gracia Rowan Douglas Williams, fue un verdadero don de Dios y un precioso testimonio cristiano.

Mucha atención apreciado lector: fijémonos que el primero de los nombrados pertenece a la Iglesia Católica Ortodoxa, a la que hemos hecho alusión acerca del sacramento del matrimonio hasta por tres veces por razones pastorales bajo ciertas condiciones.

Pero el punto del ecumenismo que aquí nos interesa mucho en cuanto a la posibilidad de que la Iglesia Católica Romana adopte la teoría y praxis de la Iglesia Católica Ortodoxa como muestra de ese ecumenismo, continúa con el siguiente numeral; veámoslo:

i. Numeral 246:

1. Dada la gravedad del antitestimonio de la división entre los cristianos, particularmente en Asia y África, la búsqueda de caminos de unidad se vuelve urgente. Los misioneros en esos continentes mencionan reiteradamente las críticas, quejas y burlas que reciben debido al escándalo de los cristianos divididos. Si nos concentramos en las convicciones que nos unen y recordamos el principio de la jerarquía de verdades, podremos caminar decididamente hacia expresiones comunes de anuncio, de servicio y de testimonio. La inmensa multitud que no ha acogido el anuncio de Jesucristo no puede dejarnos indiferentes. Por lo tanto, el empeño de una unidad que facilite la acogida de Jesucristo deja de ser mera diplomacia o cumplimiento forzado, para convertirse en un camino ineludible de la evangelización. Los signos de división entre los cristianos en países que ya están destrozados por la violencia agregan más motivos de conflicto por parte de quienes deberiamos ser un atractivo fermento de paz. ¡Son tantas y tan valiosas las cosas que nos unen! Y si realmente creemos en la libre y generosa acción del Espiritu, ¡cuántas cosas podemos aprender los unos de los otros! No se trata solo de recibir información sobre los demás para conocerlos mejor, sino de recoger lo que el Espiritu ha sembrado en ellos como un don también para nosotros...

Un signo de unidad entre los creyentes en Cristo... ¿ ¿no sería compartir y aceptar esos puntos de vista sobre el matrimonio de los católicos ortodoxos? ${ }^{15} \mathrm{Y} \ldots$ ¿. ¿no están dadas las condiciones ya con esta Exhortación Apostólica centrada en la misericordia, como centrados en la misericordia en este punto están los católicos ortodoxos?

${ }^{15}$ El documento del Sínodo, lamentablemente, no hace alusión a la teoría y praxis de la Iglesia Católica Ortodoxa a pesar del ecumenismo propio de la iglesia conciliar. 
Es lo que también proponía en el artículo de mi autoría mencionado al comienzo de estas reflexiones.

\section{Conclusiones}

Al llegar al final se expresan algunas conclusiones, al menos parciales:

El punto central de esta reflexión es la misericordia divina, tal como el papa Francisco lo propone desde su mismo escudo pontifical: "MISERANDO ATQUE ELIGENDO": he elegido la misericordia. Si no se toma tal misericordia divina como el eje alrededor del cual giramos ahora -y se debe girar siempre-, podría caerse en una maldita adaptación del Evangelio a los caprichos humanos, tal como lo dice san Pablo: "si alguien les anuncia un evangelio diferente del que ya recibieron, que caiga sobre él la maldición de Dios” (Gál. 1, 9).

Y no sobra añadir que el "tiempo de la misericordia divina" fue revelado por Jesús a santa Faustina Kovalska, razón por la cual el papa Juan Pablo II estableció en la Iglesia universal la festividad de Jesús misericordioso.

Con la Evangelli Gaudium, creo, se han abierto las puertas a los católicos en situación matrimonial irregular para que se sientan acogidos sacramentalmente, desde luego con ciertas exigencias pastorales.

Creo que no se trata tanto de establecer normas jurídicas nuevas - para no caer quizá en el normativismo iuspositivista, tan ajeno a Cristo y a la Iglesia-, cuanto de que los católicos se sientan acompañados por los pastores, en lo más íntimo de su conciencia bien formada para hacer un discernimiento y elección adecuados en cuanto cristianos ${ }^{16}$. Pero aquí cabe recordar también, y como contrapeso necesario a lo anterior, un punto de la misma Evangelii Gaudium a propósito de la vida civil en general, que cae muy bien para el tema abordado: "reconozcamos que una cultura, en la cual cada uno quiere ser el portador de una propia verdad subjetiva, vuelve difícil que los ciudadanos deseen integrar un proyecto común más allá de los beneficios y deseos personales" (numeral 61); lo traigo a colación porque en este artículo no se hace un llamado a la atomización doctrinal y moral en el punto tratado, sino a una toma de conciencia seria, reflexiva, armoniosa, cristiana en una palabra.

${ }^{16}$ Lo dice expresamente el Sínodo 2014 en el numeral 42: "un tal discernimiento es indispensable para los separados y divorciados". 
E1 Sínodo ordinario sobre la Familia, que la Iglesia adelantará en el año 2015, es de esperar que se inspire poderosamente en esta Exhortación Apostólica del papa Francisco, así como en el Sínodo Extraordinario de los Obispos del año 2014. El papa es el sucesor de san Pedro y sobre él se edifica la Iglesia. A él se le dio el poder de atar y desatar, según las propias palabras de Jesús.

\section{Referencias}

Código de Derecho Canónico (1984). BAC. Madrid.

Durán, J. G. (2013). La salvación de las almas y la imposibilidad de un nuevo matrimonio sacramental. Disponible en http://dx.doi.org/10.15425/redepriv.51.2014.11. Documento extraído el 3 de marzo de 2013

Juan Pablo II. (1981). Familiaris consortio. Bogotá: Editorial San Pablo.

Kasper, W. (2013). Aciprensa. Disponible en http://.www.aciprensa.com

Ludwig, H. (1979). Historia de la Iglesia. Barcelona: Editorial Herder.

Papa Francisco. (2014). Evangelii Gaudium. Roma, Italia: Editorial San Pablo.

Spadaro, A. (2013). La religión en el marco de la iglesia católica. Disponible en http://www. aciprensa.com/noticias

Synod14. (2013). Undécima congregación general: Relatio post disceptationem del relator general, cardenal Péter Erdö, Sala Stampa della Santa Sede. Disponible en http://press.vatican.va/ content/salastampa/es/bolletino/

Valli, A. (2013). Historia de un hombre. Bogotá, Colombia: San Pablo. 